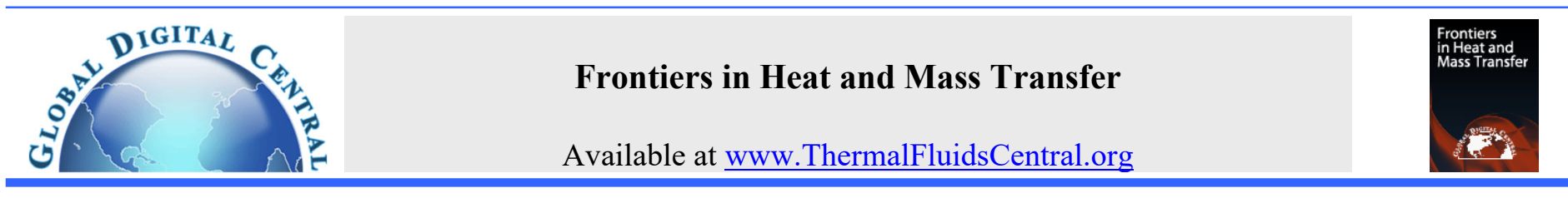

\title{
THE IMPACT OF ALUMINA NANOPARTICLES SUSPENDED IN ETHYLENE GLYCOL ON THE PERFORMANCE EFFICIENCY OF A DOUBLE PIPE HEAT EXCHANGER
}

\author{
Firas Aziz Ali, ${ }^{\text {a, }}$, Adnan M. Alsaffawi ${ }^{\text {, }}$, Karam Hashim Mohammed ${ }^{\mathrm{a}}$ \\ ${ }^{a}$ Northern Technical University, Mosul-41001, Iraq \\ ${ }^{b}$ University of Mosul, Mosul-41001, Iraq
}

\begin{abstract}
The augmentation of the heat transfer in heat exchangers is one of the methods to increase efficiency of the system. The double tube heat exchanger is selected to many suitable techniques of heat transfer enhancement. In this study; the friction factor and heat transfer coefficient of double tube is evaluated experimentally. The $\mathrm{Al}_{2} \mathrm{O}_{3}$ nanoparticles dispersed in ethylene glycol (EG) with a diameter $50 \mathrm{~nm}$ and the weight concentration $(0.1 \%, 0.3 \%$, $0.5 \%, 0.7 \%, 1 \%$ ) has been utilized. Then the effect of parallel current and counter current with different ranges of Reynolds number $(10,000$ to 30,000$)$ on the friction factor and heat transfer coefficient experimentally examined then selected the best current flow. Thermophysical properties (density, viscosity) are measured and validated with experimental data of the other researches. Result showed that the friction factor decreases with increasing of Reynolds number and increases with increasing of weight concentration but Nusselt number increases with increasing of Reynolds number and concentration of weight. It was concluded that the utilizing of alumina nanoparticles suspended in EG through a double pipe heat exchanger is significant enhancement of heat transfer. The results indicate that the alumina dispersed in EG nanofluid can enhance thermophysical properties of EG to $20 \%$. Likewise, the friction factor is slightly higher than that of pure EG and the nanofluid heat transfer is higher than the pure EG.
\end{abstract}

Keywords: Nanofluid; Heat Transfer Coefficient; Friction Factor; Thermophysical Properties.

\section{INTRODUCTION}

In recent years, there has been more attention to enhance heat transfer performance by convection of nanofluids. Nano fluid is a nanoparticle that its diameter is in the range of $(1-100 \mathrm{~nm})$ it is may be solid metallic and non-metalic materials dispersing in a base fluid such as ethylene glycol glycerol, oil and water. There are many applications of thermo fluid system: different types of heat exchanger (heat pipe, car radiator, double pipe Heat exchanger, shell tube heat exchanger). In this present study selected double pipe heat exchanger for the following reasons; this type is widely used in many application, create large heat transfer surface area, small size, easy and good mechanical design easy maintenance. Also it has disadvantages such as; its cost is relatively high, for high thermal load.

Choi et al. (1995) was the first one introduced and used the term nanofluids. It was found difference among bulk materials and nanoparticles due to suspension in liquids. The higher specific surface area of nanoparticles compared to the bulk material is due to the size materials which is $100 \mathrm{~nm}$ for nanoparticles and in micrometer for bulk materials. Choi et al. (1995) demonstrated the addition of solid nanoparticles less than 0.01 concentration of volume to liquids improve thermal conductivity of these liquids up to 2 times. Pak and Cho., used two different metallic oxide particles $\left(\mathrm{AL}_{2} \mathrm{O}_{3}, \mathrm{TiO}_{2}\right)$ as nanoparticles with $(13,27) \mathrm{nm}$ size diameter respectively in a circular tube. Results showed that Reynolds number and Nesselt number increased with volume concentration of the suspended nanoparticles. The viscosities of the $\left(\mathrm{AL}_{2} \mathrm{O}_{3}-\mathrm{TiO}_{2}\right)$ nanoparticles suspended in liquid at a $0.1 \%$ volume fraction are approximately 2 and 3 times as compared to the pure water respectively.

Maddah et al. (2014) studied the effect of mass flow rate, volume fraction of nanoparticles and temperature on the overall heat transfer coefficient. The heat transfer enhancement was about (10 to $20 \%$ ) when comparison the double pipe H.E with (twisted tape, nanofluid), and (without twisted tape) respectively. The experimental results presented that tetania nanofluid with $0.01 \%$ volume concentration and twisted tape has slightly higher pressure drop and friction factor at the same volume concentration when compared to nanofluid without twisted tape. Cao and Ding (2014) were prepared sample $\mathrm{AL}_{2} \mathrm{O}_{3}$ nanofluid at a different volume concentration with two kinds of commercially available alumina nanoparticles/suspensions and used in double pipe H.E with forced convection. They found the large error between thermal couple and the tube surface were brought by the real inhomogeneity of the heat flux and the interface heat resistance. It was shown that the thermal conductivities of $\mathrm{AL}_{2} \mathrm{O}_{3}$ nanofluid increases with nanoparticles concentration in a linear fraction at high concentration.

Al- Maghlany et al. (2016) used $\mathrm{Cu}$ nanoparticles with size diameter $20 \mathrm{~nm}$ and (1-3) \% volume fraction suspended in pure water. The test section was a rotation inner tube when its speed was up to 500 r.p.m, adjusted to the value of desired by electrical heater. They found that the Reynolds number for different volume concentration and different rotational speed is the same, and it only depends on the pure water properties of the cold fluid and longitudinal flow velocity during this study when used alumina nanoparticles and water suspension. It was observed that the enhancement effect of viscosity was minimizing at a lower value of the volume concentration. It was shown Reynolds number increases which cause to increase the overall heat transfer coefficient of

\footnotetext{
* Corresponding Author. Email: proftalib444@gmail.com
} 
nanofluids (Raghulnath and Surendran). It was $12 \%$ of the overall heat transfer enhancement for $2 \%$ concentration of volume as compared to pure water. Hussein et al. (2016) were studied the specifications effect of the tube cross sectional area on the heat transfer and pressure drop. Heat transfer enhancement and friction factor evaluated numerically for three horizontal tubes shapes that selected with four volume fractions from $1 \%$ to $2.5 \% \mathrm{TiO} 2$ dispersed in water. Their results had a good agreement with deviation $2 \%$ when compared with experimental data available in the literature.

Ibraheem et al. (2020) were studied the alumina nanoparticles suspended in water which used in a straight channel heated by solar radiation. It was measured the nanofluid thermophysical properties to evaluate the thermal characteristics. It was shown that the friction factor decreased as increase in velocity and increased as increase in viscosity. Nusselt number was increased as increase in the flow rate and volume fraction. It was concluded the alumina nanofluid might be slightly increased in friction factor and $54 \%$ in heat transfer.

The influence of hybrid nanofluid volume fraction and temperature on viscosity of aluminum oxide and multi-walled carbon nanotubes in a mixture of $20 \%$ ethylene-glycol and $80 \%$ water was experimentally studied by Afshari et al. (2018). Results showed that the power law index and consistency index were occurred by accurate curve fitting of nonNewtonian behavior of nanofluids samples. It was concluded that the apparent viscosity generally increases with increasing of the nanofluid volume concentration.

An artificial neural network (ANN) method has been investigated by Rostami et al. (2020). It was predicted the thermal conductivity of silica nanoparticles suspended in (50:50) water-ethylene glycol. Results showed that the correlation coefficient for ANN output was 0.993861 for eight neuron numbers.

An algorithm of Zinc Oxide ( $\mathrm{ZnO})-$ Silver $(\mathrm{Ag})(50 \%-50 \%) /$ Water nanofluid has been proposed to evaluate the best neuron number in the Artificial Neural Network (ANN) by He et al. It had better ability in predicting the nanofluid thermal conductivity with temperature and the nanoparticles volume fraction. It was concluded the maximum absolute value with 0.0095 error and $1.6684 \mathrm{e}-05$ train performance. Soltani et al. (2020) were investigated the experimental analysis to measure the WO3MWCNTs/Engine Oil thermal conductivity and establishing a new significance. The hybrid nanofluid thermal conductivity was increased by $19.85 \%$ compared to the base fluid at $\mathrm{T}=60^{\circ} \mathrm{C}$ and $\phi=0.6 \%$. Aghayari et al. (2014) investigated overall heat transfer coefficient of $\mathrm{AL}_{2} \mathrm{O}_{3}$ nanoparticles experimentally where impacts of Reynolds number, volume fraction, temperature and nanoparticle have been sources.

Aghayari (2014) investigated the Nusselt number and enhancement of heat transfer coefficient of $\mathrm{AL}_{2} \mathrm{O}_{3}$ /water nanofluid 0.1 and $0.3 \%$ concentration of volume and $20 \mathrm{~nm}$ size of diameter. Also demonstrated that Nusselt number and heat transfer coefficient increased significantly more than $19 \%$ and $24 \%$ respectively. In addition, the heat transfer increased with the nanoparticles volume fraction and operating temperature. Sarafraz and Hormozi (2014) studied the carbon nanotube water based nano fluid to enhance the thermal conductivity near up to 56 present, like, CNT Nano fluids that's having higher convective heat transfer coefficient in comparison with water, which is due to longer stability of internal thermal conduction of CNTs. The reason to select alumina nanoparticles suspended in ethylene glycol is to improve the efficiency of the double pipe heat exchanger with reducing the pressure drop.

\section{EXPERIMENTAL TEST RIG AND MEASUREMENT}

The friction factor and heat transfer coefficient of double tube is evaluated experimentally. The alumina solid nanoparticles dispersed in EG with a diameter $50 \mathrm{~nm}$ and the weight concentration $(0.1 \%, 0.3 \%$, $0.5 \%, 0.7 \%, 1 \%$ ) has been utilized in the ranges of Reynolds number (10000 to 30000). Validation of thermophysical properties (density, viscosity) has been conducted with experimental data of the other researches.

The experimental test rig has been fabricated to measure the outlet, inlet temperature and pressure drop to evaluate friction factor and Nusselt number as shown in Fig. 1. It is included of a tank in cold section for reserving cold fluid, one centrifugal pump, oil manometer tube, water heater, double tube heat exchanger, flow meter, valves, tubes and four digital thermocouple type $T$. The range of flow meter is between (5-40 LPM) and one valve to control flow rates has been used.

The centrifugal pump $(0.5 \mathrm{hp})$ pumped the cold fluid from the reservoir cold tank to the flow meter then to the inner tube of a heat exchanger at the flow rates (5.6-16.9) LPM. A (10 litters) volume of cold fluids utilized in all experiment's step. Two thermocouples joined at the inner tube outlet and inlet to measure the cold fluid temperature. And two other thermocouples also connected to the outer tube outlet and inlet to measure the hot fluid temperature in the secondary cycle.

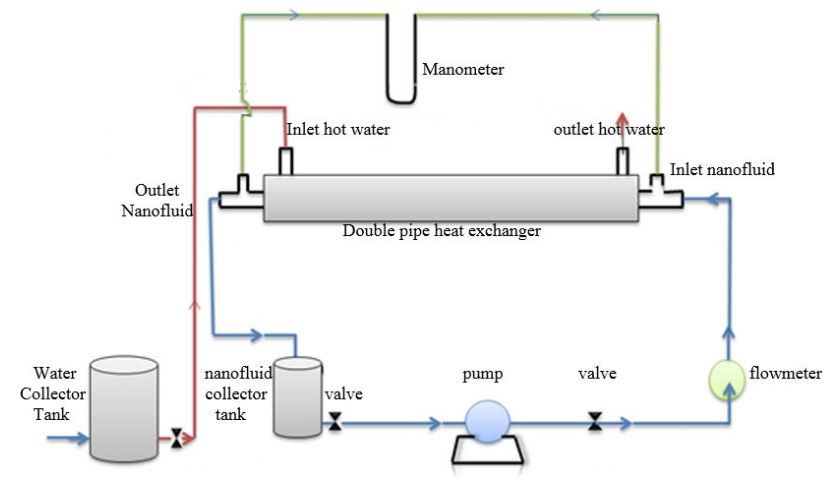

Fig. 1 Setup of experimental test rig.

Thermocouples have been calibrated with glass thermometer and variable temperature baths water which evaluated accuracy was $\left(0.5^{\circ} \mathrm{C}\right)$. Two small tubes with $8 \mathrm{~mm}$ diameters were connected to the oil U-tube manometers to measure the pressure drop. Before running the experiment, the test rig must be cleaned to remove scale or particle inside it after preparing nanofluid and introducing it to the container the temperature of hot water set at $\left(70^{\circ} \mathrm{C}\right)$ then running the experiments and set the flow rate of each loop and must be taking enough time to reach the system to the steady state more details about types of instrument used in this study is in Table1.

Table 1 Instruments details used in this study.

\begin{tabular}{lcll}
\hline Instruments & Number & Type & Accuracy \\
Thermometer & 4 & Digital & $\mp 0.5^{\circ} \mathrm{C}$ \\
$\begin{array}{l}\text { Water pump } \\
\text { Flow meter }\end{array}$ & 1 & $\begin{array}{l}\text { Centrifugal }, 0.5 \mathrm{hp} \\
\text { Flow-sp, G } 1.0\end{array}$ & $\mp 1.8$ \\
Water heater & 1 & $1200 \mathrm{watt}, 5 \mathrm{AMP}$, & $\mp 0.1 \%$ \\
& & & at $20^{\circ} \mathrm{C}$. \\
PH meter & 1 & Pen type & $\mp 0.1 \%$ \\
$\begin{array}{l}\text { Magnetic stirrer } \\
\text { Compact scale }\end{array}$ & 1 & $\begin{array}{l}\text { Hand mixer } \\
\text { Digital }\end{array}$ & $\mp 1.1 \%$ \\
\hline
\end{tabular}

To prepare nanofluid; nanoparticle must be dispersing in a base fluid as a base fluid., Generally, there are methods using in preparation processes these are: - (acid treatment of base fluid, dispersant addition, ultra- 
sonication method by using ultrasonic vibration). In this current study $30 \mathrm{~nm}$ size diameter of alumina solid nanoparticles suspended in EG as a basefluid at a concentration $(0.1 \%, 0.3 \%, 0.5 \% 0.7 \%$ and $1 \%)$ which determined the volume fraction by the Eq. (1) Ramachandran et al.

$\emptyset=\frac{\frac{m_{p}}{\rho_{p}}}{\frac{m_{f}}{\rho_{\mathrm{f}}}+\frac{m_{p}}{\rho_{p}}}$

The alumina solid nanoparticles and EG properties have been indicated in Table 2.

Table 2 Alumina and EG properties

\begin{tabular}{|l|l|l|}
\hline & Alumina & EG \\
\hline Density & $4000 \mathrm{~kg} / \mathrm{m} 3$ & $1100 \mathrm{~kg} / \mathrm{m} 3$ \\
\hline thermal conductivity & $36 \mathrm{~W} / \mathrm{m} . \mathrm{K}$ & 0.23 \\
\hline Viscosity & & $13.646 \mathrm{mPas}$ \\
\hline
\end{tabular}

For one percentage of concentration mixed 10gram nanoparticle with ( $10^{4}$ gram pure water) then used hand mixer for stir Nano fluid to be homogeneous mixture for about (20-40) min, then ultranicator used for ultrasonic method for more than $1 \mathrm{hr}$ for break up any particle agglomeration.

Viscosity is an important indicator in the evaluation of the thermophysical properties of nanofluids. A commercial Brookfield DVI prime viscometer (shown in Fig. 2 was used to measure viscosity at different temperatures and rpm. It was used for non-Newtonian and Newtonian liquids for large viscosity range values $(1-550 \mathrm{cP})$ depending on the spindle.

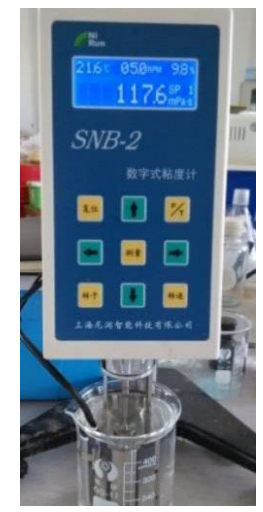

Fig. 2 viscosity equipment.

The low viscosity fluid is more accurate for this instrument between 1 and $5 \mathrm{cP}$. Moreover, same shear rate everywhere with this geometry has been allowed and different values of shear rate may be tested by setting a rotation velocity (rpm) range to expect the liquid behavior rheological and viscosity determined as well as controlled of the torque value.

Following that, the cylinder was connected carefully on the viscometer after eight minutes of water bath, the sample is tested to find the lower and upper rpm limits and taking into account their values of torque. When these values were found, the setting of program has been adopting depending to the previous values calculated limit. EG has been utilized for calibration, following which nanofluids has been used to measure viscosity. However, the apparatus of viscometer has been calibrated factory which checked for accuracy.

The $\mathrm{pH}$ test is one of important instrument to measure the stability of Nano fluid in this present study; (PH-009, pen-type measurement) as shown in Fig. 4 were used to measure the $\mathrm{pH}$ of Nano fluid before and after tests. The scientific instrument to measure the hydrogen-ion activity in liquid solutions is defined as $\mathrm{pH}$ meter which showing its expressed of alkalinity or acidity. It was measured the electrical potential difference between the reference electrode and $\mathrm{pH}$ electrode. The electrical potential difference is related to the solution $\mathrm{pH}$ or acidity. It is referring to change in thermo physical properties and stability of Nano fluid. The value of PH must keep low for Nano fluids stability (Sarafraz et al. (2016).

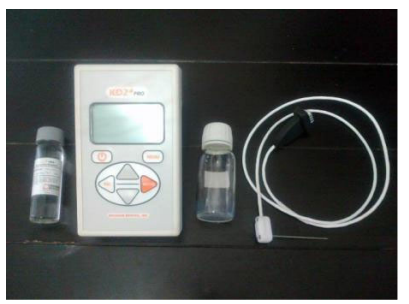

Fig. 3 KD2 Pro hot wire meter of thermal conductivity.

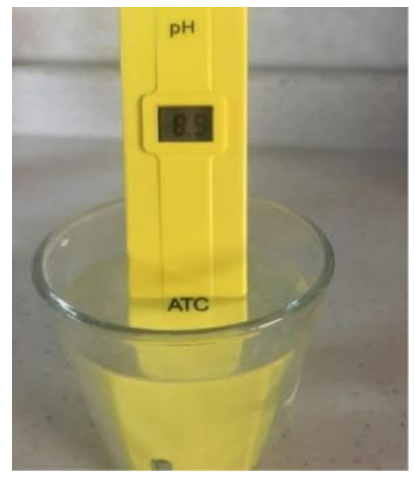

Fig. 4. PH measurements with a different volume concentration.

The thermal conductivity of nanofluid is measured with KD2 Pro thermal property analyzer of Decagon Devices, Inc., USA. The KD2 Pro used transient line heat source to measure the liquids and solids thermal properties. It consists of a handheld controller (power control and microcontroller) and two different sensors for measuring the thermal conductivity of liquids and solids. The apparatus meets the standards of both IEEE 442-1981and ASTM D5334. ASTM D5334 is the standard test method for determination of thermal conductivity of soft rock and soil by thermal needle probe procedure, whereas guided by IEEE 442 1981 for measurements of soil thermal resistivity.

For the present sample the KS-1 sensor is used to evaluate the thermal conductivity as illustrated in Fig. 3. The sensor is calibrated by evaluating the glycerin thermal conductivity. The measured value at room temperature is $0.280 \mathrm{~W} / \mathrm{mK}$ for glycerin, which is in agreed with values in literature of $0.285 \mathrm{~W} / \mathrm{mK}$ within $\pm 2.5 \%$ accuracy.

\section{DATA PROCESSING}

Heat transfer can be estimated for hot loop or (water section) by the following equation (Reddy, V. V. Rao):

$\mathrm{Q}_{\text {hot }}=\mathrm{m}_{\mathrm{w}} \mathrm{cp}_{\mathrm{w}}\left(\mathrm{T}_{\mathrm{in,w}}-\mathrm{T}_{\text {out }, \mathrm{w}}\right)$

Heat transfer for cold side or (nanofluid section) is as following equation:

$\mathrm{Q}_{\text {cold,nf }}=\mathrm{m}_{\mathrm{nf}} \mathrm{cp}_{\mathrm{nf}}\left(\mathrm{T}_{\mathrm{in}, \mathrm{nf}}-\mathrm{T}_{\text {out }, \mathrm{nf}}\right)$

where $\mathrm{Q}_{\text {hot }}$ and $\mathrm{Q}_{\text {cold,nf }}$ are the rate of heat transfer to hot water and cold nanofluid, respectively. 
And the average heat transfer rate can be defined as the following equation:

$\mathrm{Q}_{\mathrm{avg}}=\frac{\mathrm{Q}_{\text {hot,w }}+\mathrm{Q}_{\text {cold, } \mathrm{nf}}}{2}$

$\mathrm{Q}_{\mathrm{avg}}:-$ mean average rate of heat transfer

The coefficient of heat transfer equation is utilized:

$\mathrm{U}_{\mathrm{nf}}=\frac{\mathrm{Q}_{\mathrm{avg}}}{\mathrm{T}_{\mathrm{W}}-\mathrm{T}_{\mathrm{b}, \mathrm{nf}}}$

Then can be calculated the Nusselt number respectively through the Eq.(9):

$\mathrm{Nu}=\frac{\mathrm{U}_{\mathrm{nf}} \mathrm{Di}}{\mathrm{k}_{\mathrm{nf}}}$

The outer surface area of Inner tube can be estimated as:

$A_{o}=\pi . D_{0} . L$

The inner area of inner tube can be calculated as:

$\mathrm{Ai}=\pi . \mathrm{Di} . \mathrm{L}$

The Mean Temperature Logarithmic Difference (LMTD) can be evaluated as:

$\mathrm{LMTD}=\left[\left(\mathrm{T}_{\mathrm{hi}}-\mathrm{T}_{\mathrm{ci}}\right)-\left(\mathrm{T}_{\mathrm{ho}}-\mathrm{T}_{\mathrm{co}}\right)\right] / \ln \left[\left(\mathrm{T}_{\mathrm{hi}}-\mathrm{T}_{\mathrm{ci}}\right) /\left(\mathrm{T}_{\mathrm{ho}}-\mathrm{T}_{\mathrm{co}}\right)\right]$

\section{RESULTS AND DISCUSSION}

First experiment runs with pure water in both section in parallel current and counter current then compared between the overall heat transfer coefficient for each current which estimated by the Eq. (7), and friction factor for counter and parallel current as the following equation Hussein et al. (2013).

$f=\frac{2 D \Delta p}{\rho l v^{2}}$

As shown in Fig. 5 that the friction factor of counter current is lower than that of parallel current, but the overall heat transfer coefficient is higher therefore selected counter current in this study to enhance performance efficiency.

The viscosity experimental data has been shown in Fig. 6 with a concentration (1-4\%) then compared with the value of viscosity before and after test with viscosity of pure water and viscosity from the Eq. (7), as see the viscosity increases with increasing the volume fraction.

$\mu_{\mathrm{nf}}=\mu_{\mathrm{bf}}\left(1+\frac{5}{2} * \emptyset\right)$

Fig. 7, illustrates the friction factor changing with the volume fraction. The friction factor is slightly increased with volume fraction of nanofluid due to increase of nanofluid viscosity but decreases with increasing of Reynolds number. Furthermore, the friction factor of nanofluid is increased as compared to Blasuis Eq. (12) that illustrated as a solid black line.

$\mathrm{f}=0.316 \mathrm{Re}^{0.25}$

In the current experimental study, the volume concentration $0.1 \%, 0.3 \%, 0.5 \%, 0.7 \%$ and $1 \%$ and flow rate are $(5.6,8.4,11.2,14,16.9)$ $\mathrm{L} / \mathrm{min}$ with cold and hot fluid inlet temperature are $(300,343) \mathrm{K}$ respectively.

Fig. 8 shows the heat transfer coefficient at different concentration and Reynolds number as fluid flow rate using. It was noted that the heat transfer increases with increasing volume fraction as well as with increasing fluids velocity or Reynolds number.

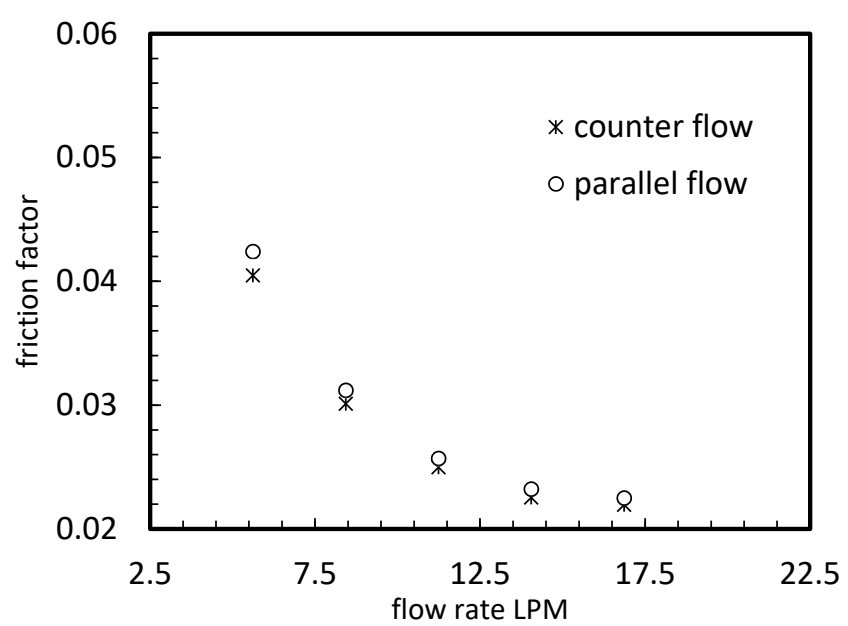

(a) friction factor at different flow rates.

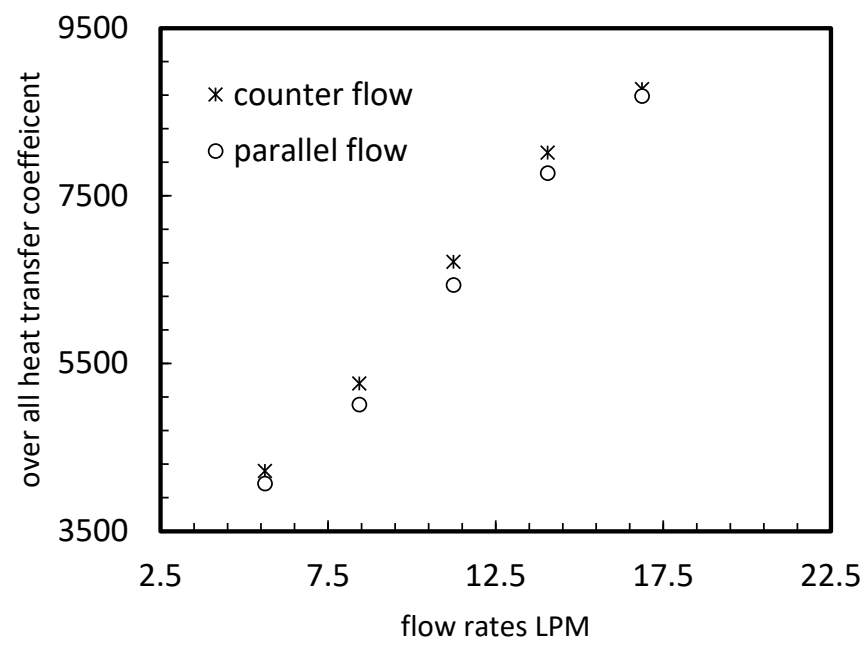

(b) overall heat transfer coefficient at different flow rates.

Fig. 5 comparison between friction factor and heat transfer coefficient of parallel and counter current at different flow rates.

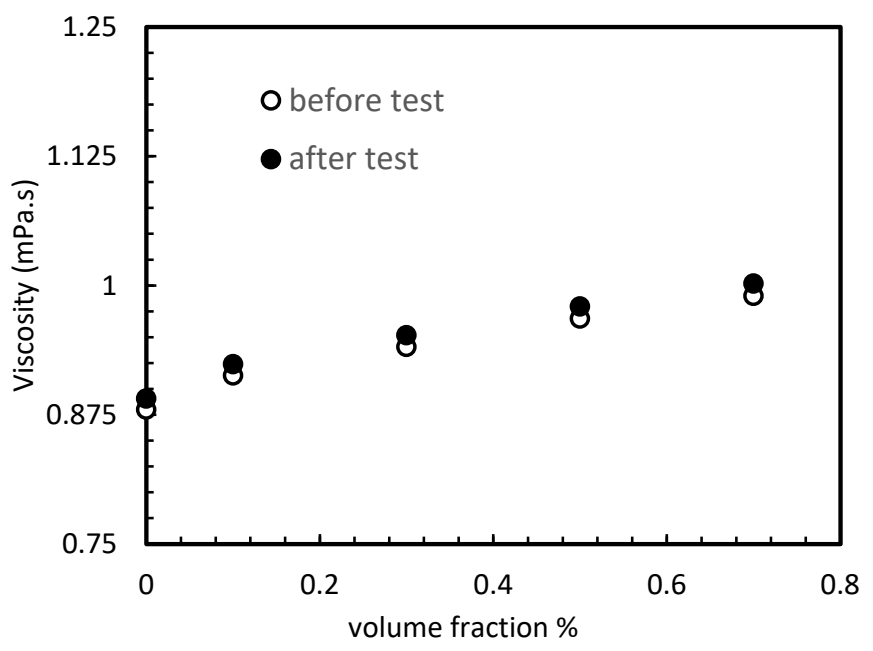

Fig. 6 experimental viscosity data with different volume fraction. 


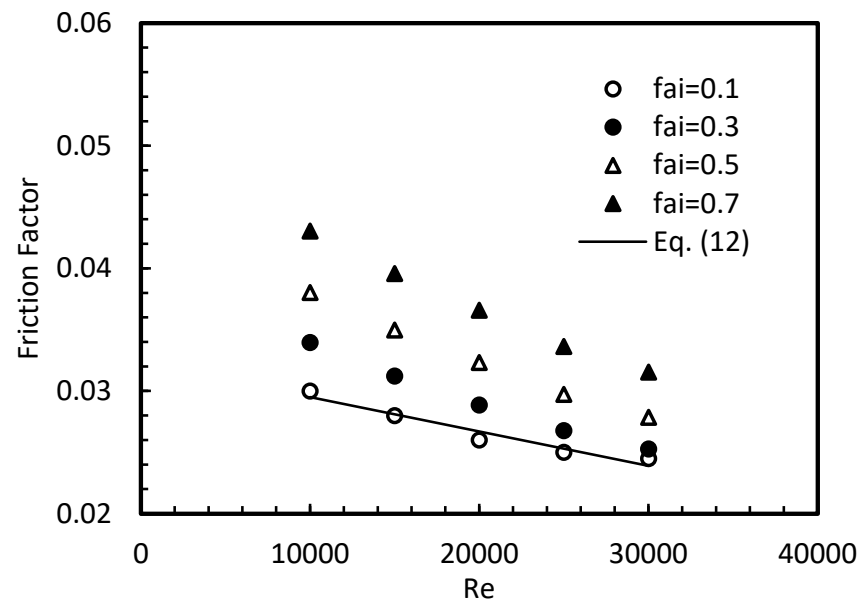

Fig. 7 effect of nanofluid volume fraction on friction factor at different Reynolds number.

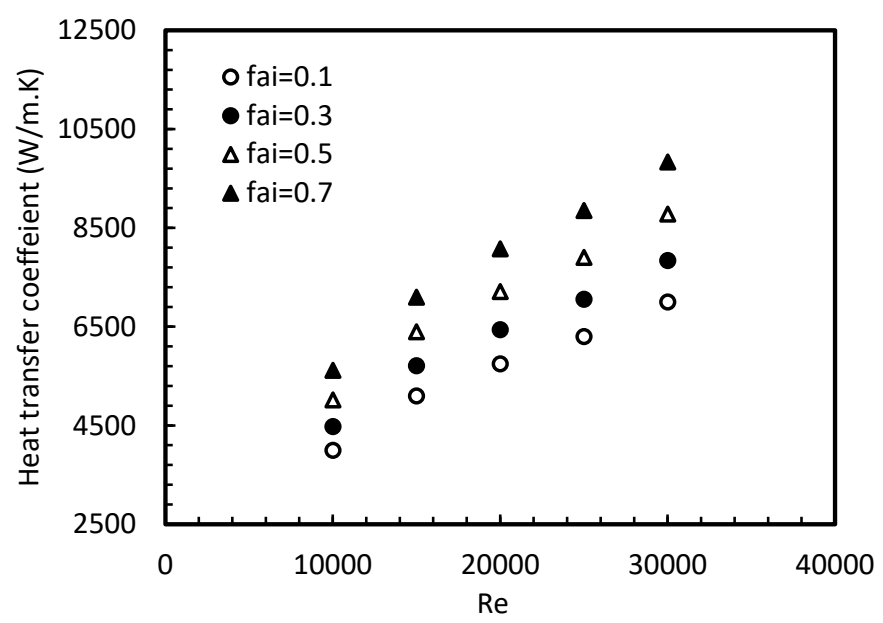

Fig. 8 experimentally overall heat transfer coefficient at different flow rates.

Fig. 9 illustrates the experimental data validation with increasing of Reynolds number. Fig. 9a showed that Nusselt number with Dittus Boilter Eq. (13) and data of researchers (Aghayari et al. (2014), Aghayari (2014), Sarafraz et al. (2016), Ramachandran et al. (2018), Hussein (2017)). It was observed that the Nusselt number behaviors was agreed with data available with deviation not more than $4 \%$.

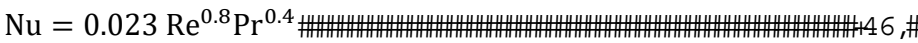

Likewise, Fig. 9b indicated that friction factor validation with data of researchers (Aghayari et al. (2014), Aghayari (2014), Sarafraz et al. (2016), Ramachandran et al. (2018), Hussein (2017)). It can be seen that the friction factor behaviors were agreed with data available with deviation not more than $3 \%$.

The mixing solid nanoparticles with EG as a base fluid increases the Efficiency and heat transfer power with reducing the production and operational costs Therefore, it is reducing the pumping power with increasing of efficiency. It can be noted the increase of efficiency and heat transfer will decrease the destructive impacts of energy on the environment.

The significant reason to enhance and producing higher heat transfer coefficient is collision between the nanoparticle and heating surface. This means that adding nanoparticles to the base fluid increases thermal conductivity and changes the fluid flow structurhv#

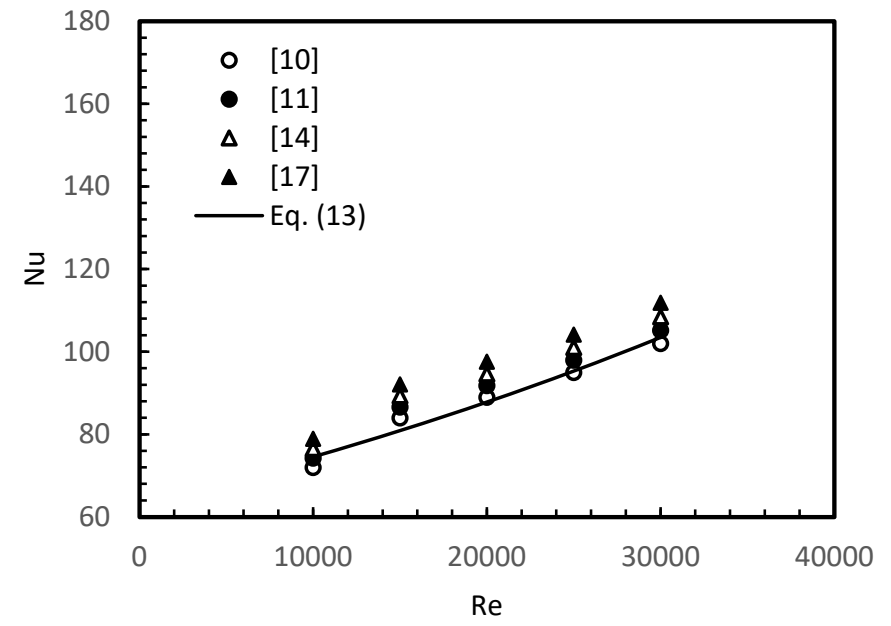

(a) Nusselt number at $1 \%$ volume fraction.\#

\#

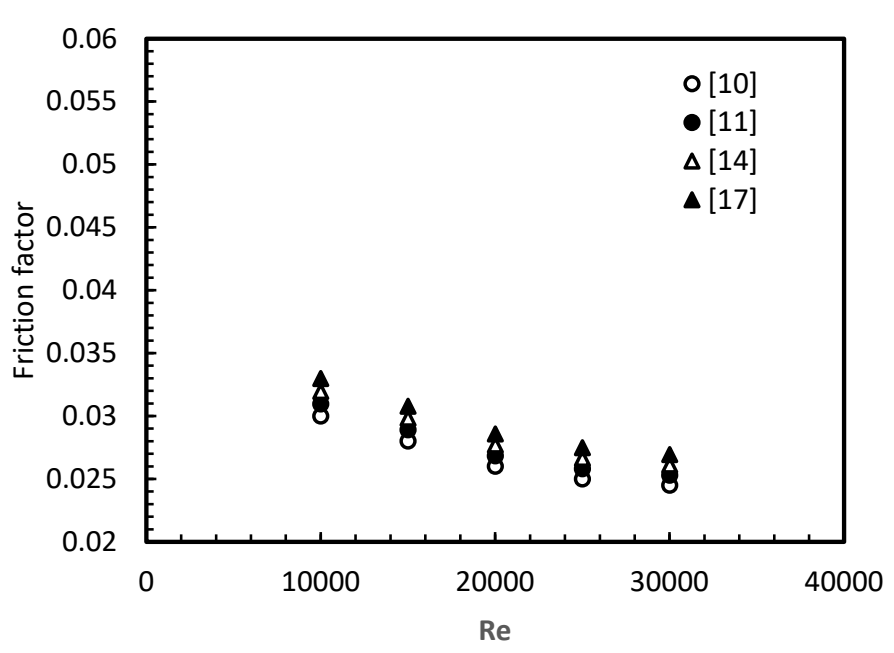

(b) friction factor at $1 \%$ volume fraction.

Fig. 9 validation of experimental data with Reynolds number.

\section{CONCLUSION}

This experimental study was performed to find the influence of $\mathrm{Al}_{2} \mathrm{O}_{3} / \mathrm{EG}$ nanofluid on performance of a double tube heat exchanger. It is indicated significant potential for convective heat transfer as a cooling system. Conclusions are summarized as following:

- $\mathrm{AL}_{2} \mathrm{O}_{3}$ nanoparticle suspended in EG can improve liquid thermal properties a bout more than $20 \%$.

- Alumina solid nanoparticles suspended in EG nanofluid is better than pure EG for heat transfer.

- Friction factor is decreased but Nusselt number is increased as flow rate of fluid increases.

- Both friction factor and Nusselt number are increased as nanofluid volume concentration increased.

\section{ACKNOWLEDGEMENTS}

The author would like to acknowledge the Northern Technical niversity.

\section{NOMENCLATURE}

$c_{p} \quad$ specific heat $(\mathrm{J} / \mathrm{kg} \cdot \mathrm{K})$ 


$\begin{array}{ll}h & \text { heat transfer coefficient }\left(\mathrm{W} / \mathrm{m}^{2} . \mathrm{K}\right) \\ k & \text { thermal conductivity }(\mathrm{W} / \mathrm{m} \cdot \mathrm{K}) \\ q^{\prime \prime} & \text { heat flux }\left(\mathrm{W} / \mathrm{m}^{2}\right) \\ T & \text { temperature }(\mathrm{K}) \\ u & \text { interfacial velocity }(\mathrm{m} / \mathrm{s}) \\ m & \text { mass } \\ \mu & \text { dynamic viscosity } \\ T & \text { temperature } \\ \rho & \text { density }\left(\mathrm{kg} / \mathrm{m}^{3}\right) \\ f & \text { friction factor } \\ \operatorname{Re} & \text { Reynolds number } \\ \mathrm{Nu} & \text { Nusselt number } \\ \mathrm{Pr} & \text { Prandtle number } \\ \text { in } & \text { inlet } \\ \text { out } & \text { outlet } \\ \mathrm{t} & \text { time } \\ \forall & \text { volume. } \\ \mathrm{LPM} & \text { liter per minute } \\ \mathrm{EG} & \text { ethylene glycol } \\ \text { fai }(\phi) & \text { volume concentration }\end{array}$

\section{REFERENCES}

Afshari A., Akbari M., Toghraie D., Yazdi M.E., 2018. Experimental investigation of rheological behavior of the hybrid nanofluid of MWCNT-alumina/water (80\%)-ethylene-glycol (20\%). Journal of Thermal Analysis and Calorimetry, 132(2), 1001-1015. https://doi.org/10.1007/s10973-018-7009-1

Aghayari R., 2014, Heat Transfer of Nanofluid in A Double Pipe Heat Exchanger. International Scholarly Research Notices, 42, pp.1- 7. https://doi.org/10.1155/2014/736424

Aghayari R., Maddah H., Ashori F., Hakiminejad H., Aghili M., 2014, Effect of Nanoparticles On Heat Transfer in Mini Doublepipe Heat Exchangers in Turbulent Flow. Heat and Mass Transfer, 51, pp. 301306. https://doi.org/10.1007/s00231-014-1415-0

S. Choi, U.S., Zhang, Z.G., Yu, W., Grulke, E.A., 1995, Anomalously Thermal Conductivity Enhancement in Nanotube Suspensions. Appl. Phys. Lett, 79, pp 2252-2254. $\underline{\text { https://doi.org/10.1063/1.1408272 }}$

Batchelor G., 1977, The Effect of Brownian Motion On the Bulk Stress in A Suspension of Spherical Particles. J. Fluid Mech. 83, pp 97-117. https://doi.org/10.1017/S0022112077001062

Bejan A., 2004, Convection Heat Transfer, New York: John Wiley \& Sons Inc.

Cao J., Ding Y., 2014, Aqueous $\mathrm{Al}_{2} \mathrm{O}_{3}$ Nano Fluids the Important Factors Impacting Convective Heat Transfer. Heat and Mass Transfer,50(12), pp.1639-1648.

https://doi.org/10.1007/s00231-014-1374-5

Hussein, A.M., Bakar, R.A., Kadirgama, K., Sharma,K.V., Heat transfer enhancement with elliptical tube under turbulent flow TiO2water nanofluid. THERMAL SCIENCE 20 (2016) 89-97. https://doi.org/10.2298/TSCI130204003H

Daniali, O. A., Toghraie, D., \& Eftekhari, S. A. 2020. Thermohydraulic and economic optimization of Iranol refinery oil heat exchanger with Copper oxide nanoparticles using MOMBO. Physica A: Statistical Mechanics and its Applications, 540, 123010. https://doi.org/10.1016/j.physa.2019.123010
Duangthongsuk W., Wongwises S., 2010, An Experimental Study on the Heat Transfer Performance and Pressure Drop of Tio2-Water Nanofluids Flowing Under a Turbulent Flow Regime. Elsevier Ltd.: International Journal of Heat and Mass Transfer. 53, pp:334-44. https://doi.org/10.1016/j.ijheatmasstransfer.2009.09.024

El-Maghlany M.Y., Hanafy A.A., Hassan A.A., El-Magid M.A., 2016, Experimental Study of $\mathrm{Cu}$-Water Nanofluid Heat Transfer and Pressure Drop in A Horizontal Double-Tube Heat Exchanger. Experimental Thermal and Fluid Science, 78. https://doi.org/ 10.1016/j.expthermflusci.2016.05.015

He, W., Ruhani, B., Toghraie, D., Izadpanahi, N., Esfahani, N. N., Karimipour, A., \& Afrand, M. (2020). Using of Artificial Neural Networks (ANNs) to predict the thermal conductivity of Zinc OxideSilver $(50 \%-50 \%)$ /Water hybrid Newtonian nanofluid. International Communications in Heat and Mass Transfer, 116, 104645. https://doi.org/10.1016/j.icheatmasstransfer.2020.104645

Hussein A.M., Bakar R.A., Kadirgama K., Sharma K.V., 2014, Heat Transfer Enhancement Using Nanofluids in an Automotive Cooling System. International Communications in Heat and Mass Transfer 53, pp. 195-202. https://doi.org/10.1016/j.icheatmasstransfer.2014.01.003

Hussein A.M., Sharma K.V., Bakar R.A., Kadirgama K., 2013, The effect of cross sectional area of tube on friction factor and heat transfer nanofluid turbulent flow. International Communications in Heat and Mass Transfer, 47, 49-55.

https://doi.org/10.1016/j.icheatmasstransfer.2013.06.007

Hussein A.M., 2017, Thermal performance and thermal properties of hybrid nanofluid laminar flow in a double pipe heat exchanger. Experimental Thermal and Fluid Science, 88 (2017) 37-45. https://doi.org/10.1016/j.expthermflusci.2017.05.015

Hussein A.M., Kadirgama K., Noor M.M., Nanoparticles suspended in ethylene glycol thermal properties and applications: An overview. Renewable and Sustainable Energy Reviews 69 (2017): 1324-1330. https://doi.org/10.1016/j.rser.2016.12.047

Hussein, A.M. Dawood, H.K. Bakar, R.A., Kadirgama,K., Numerical study on turbulent forced convective heat transfer using nanofluids $\mathrm{TiO} 2$ in an automotive cooling system. Case Studies in Therm. Eng. 9 (2017) 72-78. https://doi.org/10.1016/j.csite.2016.11.005

Li, Z., Barnoon, P., Toghraie, D., Dehkordi, R. B., \& Afrand, M. (2019). Mixed convection of non-Newtonian nanofluid in an H-shaped cavity with cooler and heater cylinders filled by a porous material: Two phase approach. Advanced Powder Technology, 30(11), 2666-2685. https://doi.org/10.1016/j.apt.2019.08.014

Lin C.Y., Wang J., Chen C., 2011, Analysis of Suspension and Heat Transfer Characteristics of $\mathrm{Al}_{2} \mathrm{O}_{3}$ Nanofluids Prepared Through Ultrasonic Vibration. Applied Energy, 88(12), Pp4527-4533. https://doi.org/10.1016/j.apenergy.2011.05.035

Maddah H., Aghayari R., Farokhi M., Jahanizadeh S., Ashtary K., 2014, Effect of Twisted-Tape Turbulators and Nanofluid On Heat Transfer in A Double Pipe Heat Exchanger. Journal of Engineering, ,70, pp.1-9. https://doi.org/10.1155/2014/920970

Maddah H., Alizadeh M., Ghasemi N., Wan S.R, 2014, Experimental Study of $\mathrm{Al}_{2} \mathrm{O}_{3} /$ Water Nanofluid Turbulent Heat Transfer Enhancement in The Horizontal Double Pipes Fitted with Modified 
Twisted Tapes. International Journal of Heat and Mass Transfer, 78, pp 1042-1054.

https://doi.org/10.1016/j.ijheatmasstransfer.2014.07.059

Hussein, A.M., Noor, M.M., Kadirgama,K., Ramasamy, D., Rahman, M.M., Heat transfer enhancement using hybrid nanoparticles in ethylene glycol through a horizontal heated tube. Int. J. of Autom. Mech. Eng. 14 (2017) 4183-4195.

https://doi.org/10.15282/IJAME.14.2.2017.6.0335

Azeez, A.F. Hameed, A.M. Hussein, Nanofluid heat transfer augmentation in a double pipe heat exchanger. AIP Conference Proceedings 2213, (2020) 020059. https://doi.org/10.1063/5.0000243

Moradi, A., Toghraie, D., Isfahani, A. H. M., Hosseinian, A. (2019). An experimental study on MWCNT-water nanofluids flow and heat transfer in double-pipe heat exchanger using porous media. Journal of Thermal Analysis and Calorimetry, 137(5), 1797-1807. https://doi.org/10.1007/s10973-019-08076-0

Pak B.C., Cho Y.I., 1998, Hydrodynamic and Heat Transfer Study of Dispersed fluids with Submicron Metallic Oxide Particles. Exp. Heat Transfer ,11, pp151-170.

https://doi.org/10.1080/08916159808946559

Raghulnath D., Surendran R., 2016, Investigation of Heat Transfer Performance of Water/Ethylene Glycol Mixture Based $\mathrm{Al}_{2} \mathrm{O}_{3}$ Nanofluids. International Conference On Current Research in Engineering Science and Technology,60, pp.124-132. https://doi.org/10.1016/j.egypro.2015.11.474

Ramachandran K., Hussein A.M., Kadirgama K., Ramasamy D., Azmi, W., Tarlochan F., Kadirgama G., 2017, Thermophysical Properties Measurement of Nano Cellulose in Ethylene Glycol/Water. Applied Thermal Engineering, 123, pp 1158-1165. https://doi.org/10.1016/j.applthermaleng.2017.05.067

Reddy M.C., Rao V., 2014, Experimental Investigation of Heat Transfer Coefficient and Friction Factor of Ethylene Glycol Water Based TiO2 Nanofluid in Double Pipe Heat Exchanger with and Without Helical Coil Inserts. Int. Commun. Heat Mass Transfer, 50 (0), pp. 68-76.

https://doi.org/10.1016/i.icheatmasstransfer.2013.11.002

Rostami S., Toghraie D., Esfahani M.A., Hekmatifar M., Sina N., (2020) Predict the thermal conductivity of SiO2/water-ethylene glycol (50:50) hybrid nanofluid using artificial neural network. Journal of Thermal Analysis and Calorimetry.
https://doi.org/10.1007/s10973-020-09426-Z

Ruhani, B., Toghraie, D., Hekmatifar, M., \& Hadian, M. (2019). Statistical investigation for developing a new model for rheological behavior of $\mathrm{ZnO}-\mathrm{Ag}(50 \%-50 \%) /$ Water hybrid Newtonian nanofluid using experimental data. Physica A: Statistical Mechanics and its Applications, 525, 741-751.

https://doi.org/10.1016/j.physa.2019.03.118

Sarafraz M., Hormozi F., 2014, Scale Formation and Subcooled Flow Boiling Heat Transfer of Cuo-Water Nanofluid Inside the Vertical Annulus. Exp. Thermal Fluid Sci. 52, Pp 205-214. https://doi.org/10.1016/j.expthermflusci.2013.09.012

Sarafraz M.M., Hormozi F., Nikkhah V., 2016, Thermal Performance of a Counter-Current Double Pipe Heat Exchanger Working with Cooh-Cnt/Water Nanofluids. Experimental Thermal and Fluid Science, 78, pp. 41-49.

https://doi.org/10.1016/j.expthermflusci.2016.05.014

Senthilraja S., Vijayakumar K., .2013, Analysis of Heat Transfer Coefficient of Cuo/Water Nanofluid Using Double Pipe Heat Exchanger. International Journal of Engineering Research and Technology, 6, pp. 675-680.

Singh K., Sharma S., Charyulu G., 2017, Experimental Study of Thermophysical Properties of $\mathrm{Al}_{2} \mathrm{O}_{3} /$ Water Nanofluid. Journal of Molecular Liquids. 237, pp. 304-312.

https://doi.org/10.1016/j.molliq.2017.04.099

Soltani, F., Toghraie, D., \& Karimipour, A., (2020). Experimental measurements of thermal conductivity of engine oil-based hybrid and mono nanofluids with tungsten oxide (WO3) and MWCNTs inclusions. Powder Technology.

https://doi.org/10.1016/j.powtec.2020.05.059

Sudarmadji, 2015, Effects of Cooling Process of $\mathrm{Al}_{2} \mathrm{O}_{3}-$ Water Nanofluid on Convective Heat Transfer. Faculty of Mechanical Engineering, Belgrade, FME Transactions, 42, pp 155-161. https://doi.org/10.5937/fmet1402155S

Zoubair B., Abderrahim W., Rachid S., 2018, Heat transfer and cuwater nanofluid flow in a ventilated cavity having central cooling cylinder and heated from the below considering three different outlet port locations. Frontiers in heat and mass transfer (FHMT) 11. https://doi.org/10.5098/hmt.11.11 